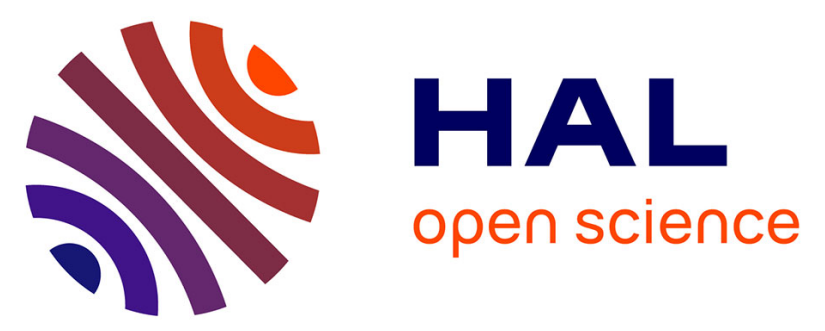

\title{
Effects of the injector design on the transfer function of premixed swirling flames
}

M Gatti, R Gaudron, Clement Mirat, Thierry Schuller

\section{To cite this version:}

M Gatti, R Gaudron, Clement Mirat, Thierry Schuller. Effects of the injector design on the transfer function of premixed swirling flames. ASME Turbo Expo 2017: Turbomachinery Technical Conference and Exposition, Jun 2017, Charlotte, United States. 10.1115/gt2017-63874 . hal-01827072

\section{HAL Id: hal-01827072 \\ https://hal.science/hal-01827072}

Submitted on 1 Jul 2018

HAL is a multi-disciplinary open access archive for the deposit and dissemination of scientific research documents, whether they are published or not. The documents may come from teaching and research institutions in France or abroad, or from public or private research centers.
L'archive ouverte pluridisciplinaire HAL, est destinée au dépôt et à la diffusion de documents scientifiques de niveau recherche, publiés ou non, émanant des établissements d'enseignement et de recherche français ou étrangers, des laboratoires publics ou privés. 


\title{
EFFECTS OF THE INJECTOR DESIGN ON THE TRANSFER FUNCTION OF PREMIXED SWIRLING FLAMES
}

\author{
M. Gatti, R. Gaudron, C. Mirat, T. Schuller \\ Laboratoire EM2C, CNRS, CentraleSupélec ${ }^{1}$, \\ Université Paris-Saclay, \\ 92295 Châtenay-Malabry cedex, France \\ Email: marco.gatti@centralesupelec.fr
}

\section{ABSTRACT}

This article reports a series of experiments on the dynamics of lean-premixed swirl-stabilized flames submitted to harmonic flowrate modulations. The flame transfer function is analyzed for different injector designs with a specific focus on conditions leading to the lowest heat release rate response for a given flowrate perturbation. Experiments are carried out at a fixed equivalence ratio and fixed thermal power. Transfer functions are measured for radial swirling vanes by modifying the diameter of the swirler injection holes, the diameter of the injection tube at the top of the swirler and the end piece diameter of a central insert serving as a bluff body. It is found that the lowest response depends on the forcing frequency and is obtained when the injector design features the largest swirl number. The transfer function of the studied flames features a minimum gain value which decreases for increasing swirl levels. This minimum value is found to be independent of the velocity forcing level and is only controlled by the level of swirl. An excessive swirl level however leads to flash-back of the perturbed flames inside the injector. The way the flame behaves at this forcing frequency is analyzed for a set of injectors featuring the same radial swirling vane design and different injection tube diameters or conical end pieces. It is found that at the condition corresponding to the lowest FTF gain, i.e. the injector with the largest swirl number, the upper and lower parts of the flame contribute to out of phase heat release oscillations, but they also both feature a reduced level of fluctuations. When the swirl number decreases, the FTF gain increases due to a reduction of the phase lag between heat release rate oscillations in the lower and the upper parts of the flame and more importantly due to a general increase of the level of heat release

\footnotetext{
${ }^{1}$ Formerly: ECP (École Centrale Paris). The name was recently changed to CentraleSupélec, Université Paris Saclay.
}

oscillations in both parts of the flame.

\section{INTRODUCTION}

The response of premixed swirling flames to flow disturbances is a topic of high scientific and technical interest due to the problems raised by their dynamic stability in gas turbine applications [1-3]. One of the issues is to better understand the frequency response of these flames to flowrate modulations through the injector. In fully premixed systems, this response is generally characterized by a transfer function between heat release rate fluctuations $\dot{Q}^{\prime}$ and harmonic velocity disturbances $u^{\prime}$ that produce them [4]:

$$
\mathscr{F}(f)=\frac{\dot{Q}^{\prime} / \bar{Q}}{u^{\prime} / \bar{u}}=G(f) \exp (i \varphi(f))
$$

where $G$ and $\varphi$ denote the gain and phase lag of the Flame Transfer Function $\mathscr{F}$ (FTF), which depend on the forcing frequency $f$. In recent developments, this linear concept has been extended to the Flame Describing Function (FDF) when effects of the perturbation level $\left|u^{\prime}\right| / \bar{u}$ are explicitly considered (see e.g. $[5,6]$ for swirling flames).

Many recent investigations of the FTF of swirling flames by modeling tools [7-9], numerical simulations $[10,11]$ and by experimental means $[2,5,12]$ indicate that the injector dynamics and the response of the swirler to flow perturbations need to be considered to interpret the main features of the FTF of swirling flames.

Hirsch et al. [7] compared the transfer functions of two different premixed flames produced by an axial swirler located at the burner exit and a radial swirler located further upstream. To 


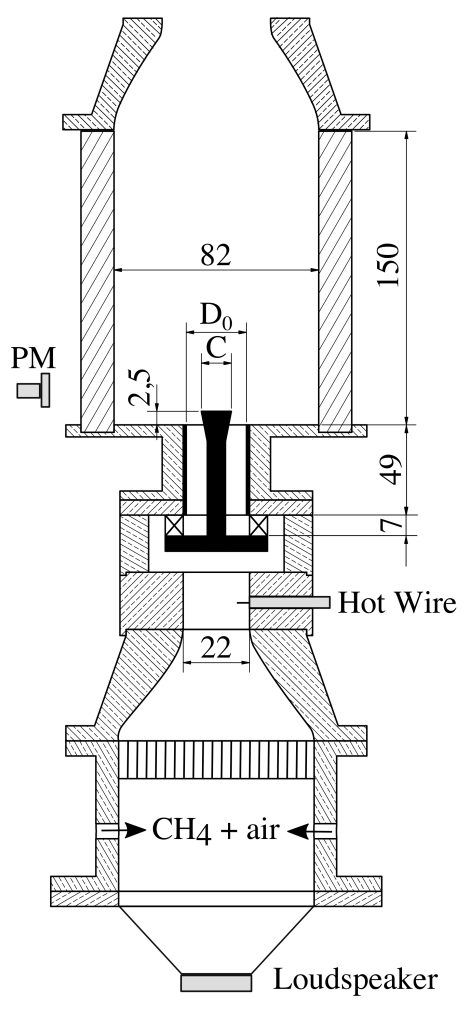

FIGURE 1. Burner sketch. The main dimensions are indicated in millimeters.

explain their results they introduced a FTF model based on the transport of vorticity. In their model, swirl number modulations result from vorticity fluctuations generated at the burner outlet and the resulting swirl number modulation is sensitive to the convective time lag between the swirler and the burner outlet. This in turn alters the FTF. Komarek and Polifke [12] found that the FTF of swirl-stabilized lean premixed flames feature a large drop of the gain level in the intermediate frequency range and that the frequency corresponding to this minimum gain value is a function of the distance between the swirler and the injector outlet. They showed by numerical simulations that this phenomenon is due to swirl number oscillations that are generated at the swirler outlet and are then convected by the mean flow.

In a series of work, Palies et al. [5, 10,13] fully interpret this mechanism and demonstrate that azimuthal waves are generated at the swirler trailing edge when the swirling vane is impinged by axial acoustic waves. These two waves lead to different responses of the swirling flame and their interference leads to an out of phase motion of the flame near its base and its tip. Models were proposed for these mechanisms and the resulting flame wrinkling process $[5,8]$. The net effect is that large swirl number oscillations at the burner outlet lead to a low FTF gain due to a balance of heat release rate oscillations produced by the angular
TABLE 1. Swirler geometrical details. $N$ : number of tangential injection holes. $D_{s}$ : diameter of an injection hole. $H$ : distance between one injection hole axis and the burner axis.

\begin{tabular}{cccc}
\hline & $N$ & $D_{s}[\mathrm{~mm}]$ & $H[\mathrm{~mm}]$ \\
\hline Swirler 2 & 6 & 6.0 & 6.0 \\
Swirler 3 & 6 & 5.6 & 4.5 \\
Swirler 4 & 6 & 5.6 & 3.5 \\
\hline
\end{tabular}

displacement of the flame root and heat release rate fluctuations produced by flame tip roll-up $[3,10]$. These two contributions to heat release fluctuations are found to be out of phase at the gain minimum. Since the level of swirl number oscillation depends on the axial distance from the swirler to the injector outlet, this mechanism is frequency dependent. When swirl number oscillations are low, heat release rate oscillations near the flame base and those at the flame tip are nearly in phase leading to a maximum value of the FTF gain.

Swirl number induced flame oscillations interfering with flame tip vortex roll-up have been confirmed by other recent experiments conducted in lean swirling premixed systems [14] as well as with swirling spray diffusion flames [15]. Large swirl number oscillations were also identified in aero-jet swirling injectors with air-blast atomizer [16]. These oscillations were shown to modify the fuel spray dynamics and droplet size distribution. Straub and Richards [17] found that the location of the axial swirling vane significantly alters the magnitude of the thermoacoustic instabilities observed in their high pressure test rig operated with preheated air.

While the mechanisms leading to swirl number oscillations are now well understood and the frequency at which the largest effects on the FTF is well predicted by considering the time lag of azimuthal wave disturbances convected by the mean flow between the swirler and the injector outlet $[5,7,12,14]$, there is yet no systematic attempt to use these swirl number oscillations to minimize the FTF gain. The objective of this work is to analyze effects of the swirler design on the FTF of premixed swirling flames and identify the main elements leading to the largest drop of the FTF gain with a set of experiments.

The experimental setup is presented in the next section, followed by an analysis of the FTF data obtained for the different injectors tested. An examination of the flame structures is then conducted for one swirler geometry at two forcing frequencies corresponding to conditions at the FTF gain minimum and maximum response. Conclusions are drawn regarding the way the flame responds to these forcing frequencies. 

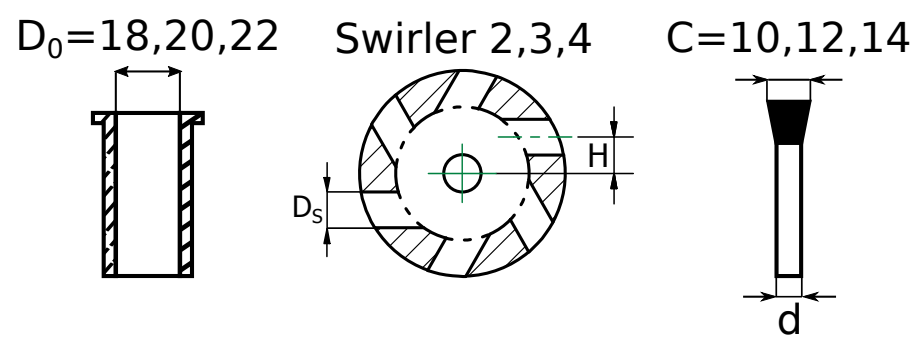

FIGURE 2. Focus on replaceable components: central injection tube, swirler, bluff-body.

\section{EXPERIMENTAL SETUP}

In the burner sketched in Fig. 1, a mixture of methane and air is injected from two diametrically opposed apertures positioned at its base. The flow crosses a grid and a honeycomb to break the largest turbulent scales. A convergent section produces a top-hat velocity profile at the location where the flow velocity is measured with a hot-wire anenometer probe (Dantec Dynamics - Probe 55P16 with a mini-CTA 54T30). The diameter of this section is $D=22 \mathrm{~mm}$.

The setup was designed to easily allow the substitution of some of the components and analyze effects of geometrical modifications on flame dynamics. The replaceable components are represented in black in Fig. 1 and detailed in Fig. 2. Three different swirlers are tested, designated as swirler 2, 3 and 4 in Tab. 1. They correspond to radial swirlers with tangential inlets consisting of $N$ cylindrical inlets of variable diameter $D_{s}$. The semidistance between the axes of two diametrically opposed inlets is $H$. The flow leaves the swirler into a central injection tube. The diameter of this tube can be modified $D_{0}=22 \mathrm{~mm}, 20 \mathrm{~mm}$ and $18 \mathrm{~mm}$. A central rod of diameter $d=6 \mathrm{~mm}$ ending with a cone of variable diameter at the top $C=10 \mathrm{~mm}, 12 \mathrm{~mm}$ and $14 \mathrm{~mm}$ is inserted in the injection tube to ease stabilization.

The chamber, made of 4 transparents quartz windows, has a squared cross-section of $82 \mathrm{~mm}$ width and $150 \mathrm{~mm}$ length. At the base of the burner, a loudspeaker (Monacor SP-6/108PRO, 100 Watts RMS) is mounted to pulsate the flow. The velocity oscillations are measured with the hot-wire. A photomultiplier (Hamamatsu, H5784-04), equipped with an $\mathrm{OH}^{*}$ filter (Asahi Spectra, ZBPA310) centered around $310 \mathrm{~nm}$, is used to measure the heat release rate fluctuations.

The equivalence ratio $\phi=0.82$ and the bulk velocity $U_{b}=$ $5.44 \mathrm{~m} / \mathrm{s}$ at the hot-wire location deduced from the air and methane mass flowrate indications (at $20^{\circ} \mathrm{C}$ and $p=1 \mathrm{~atm}$ ) are fixed for all the experiments conducted in this study. The system is thus operated at a constant thermal power $\mathscr{P}=5.44 \mathrm{~kW}$ assuming total combustion.

Laser Doppler Velocimetry is used to analyze the flow at the injector outlet. The flow is seeded in this case with small oil droplets of $3 \mu \mathrm{m}$. An intensified CCD camera (Princeton

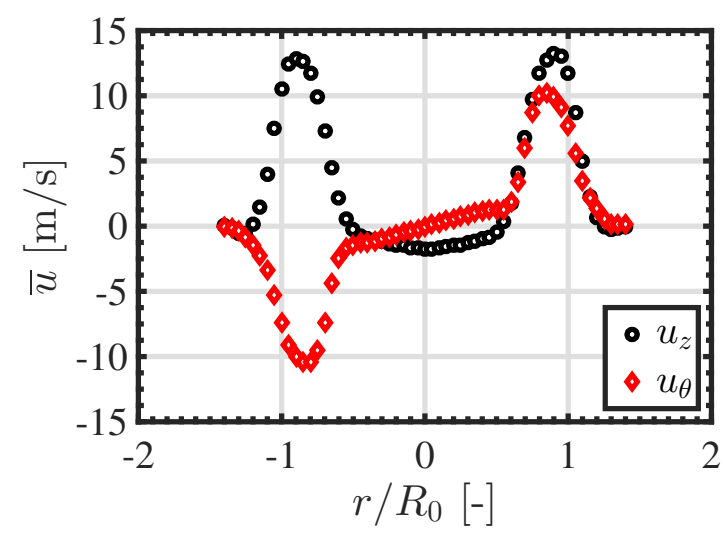

FIGURE 3. Mean axial $u_{z}$ and azimuthal $u_{\theta}$ velocity components for Swirler $3, D_{0}=20 \mathrm{~mm}$ and $C=12 \mathrm{~mm}$.

Instruments, PI-MAX 4, 1024×1024 pixels) mounted with an UV objective is used to analyze the flame structure.

\section{STEADY FLOW ANALYSIS}

The different injectors are characterized first by analyzing the outlet flow in cold flow conditions. Laser Doppler Velocimetry measurements of the axial $u_{z}$ and azimuthal $u_{\theta}$ velocity components are carried out $4 \mathrm{~mm}$ above the injector outlet, i.e. 1.5 $\mathrm{mm}$ above the top cone of the central bluff-body, with a resolution of $0.5 \mathrm{~mm}$ along the radial direction.

Results are presented in Fig. 3 for Swirler 3 (Tab. 1) and case 2 in Tab. 2 corresponding to an injection hole of diameter $D_{0}=20 \mathrm{~mm}$ with a cone of $C=12 \mathrm{~mm}$ diameter. The axial velocity profile $u_{z}$ features a central recirculation zone with negative velocities and the azimuthal velocity $u_{\theta}$ has a Rankine like shape profile in the center part of the flow. One can also check that the velocity profiles are well symmetric. The swirl number $S$ of this injector is deduced from:

$$
S=\frac{1}{R_{0}} \frac{\int u_{\theta} u_{z} r^{2} d r}{\int u_{z}^{2} r d r}
$$

where $R_{0}=D_{0} / 2$. One finds for this case $S=0.69$, a value typical of many injectors used to stabilize swirling flames. Measurements with Swirler 3 were repeated for the five cases synthesized in Tab. 2 by changing either the diameter $D_{0}$ of the injection tube or the diameter $C$ of the conical end piece.

Effects of the swirl number $S$ on the shape taken by the flames are analyzed for Swirler 3. Images of the mean turbulent flame structure are deduced by averaging a hundred snapshots recorded with the ICCD camera equipped with an $\mathrm{OH}^{*}$ filter with a long exposure time. Figure 4 shows results for a fixed conical 
TABLE 2. Configurations explored with Swirler 3 (Tab. 1). $D_{0}:$ Injection tube diameter. $C$ : conical end piece diameter. $S:$ swirl number. $\bar{I} / \bar{I}_{\text {ref }}$ : relative flame luminosity integrated over the flame volume with respect to case 2. $\Delta P[\mathrm{~Pa}]$ : pressure excess measured in the plenum just before the convergent section in Fig.1 with respect to the atmospheric value.

\begin{tabular}{cccccc}
\hline Case & $D_{0}[\mathrm{~mm}]$ & $C[\mathrm{~mm}]$ & $S[-]$ & $\bar{I} / \bar{I}_{\text {ref }}[-]$ & $\Delta P[\mathrm{~Pa}]$ \\
\hline 1 & 20 & 10 & 0.73 & 1.09 & 333 \\
2 & 20 & 12 & 0.69 & 1 & 333 \\
3 & 20 & 14 & 0.61 & 0.93 & 333 \\
4 & 18 & 12 & 0.59 & 0.87 & 372 \\
5 & 22 & 12 & 0.79 & 1.07 & 275 \\
\hline
\end{tabular}

end piece of diameter $C=12 \mathrm{~mm}$ when the injector diameter is reduced from $D_{0}=22$ to $18 \mathrm{~mm}$. The flame becomes more elongated as the swirl number indicated in Tab. 2 reduces from $S=0.79$ to 0.59 . This is due to the increase of the bulk velocity in the injection tube when its diameter is reduced. In the right image in Fig. 4, the flame begins to interact with the combustion chamber sidewalls where combustion is quenched. This is highlighted by a slight drop of the flame luminosity $\bar{I} / \bar{I}_{r e f}=0.87$ integrated over the whole flame volume, where $\bar{I}_{\text {ref }}$ is the luminosity of the flame shown in the middle in Fig. 4 corresponding to case 2 in Tab. 2. One may note as well that the flame luminosity slightly drops between the left and middle images in Fig. 4 by $7 \%$. This is again attributed to heat losses to the chamber walls. It has been shown that the $\mathrm{OH}^{*}$ luminosity of premixed swirling flames drops due to heat losses to the chamber walls even without direct interaction between the flame and the walls $[18,19]$.

The second set of images shown in Fig. 5 reveals effects of the conical end piece when its diameter is increased from $C=10$ to $14 \mathrm{~mm}$. These data were obtained for the injection tube of diameter $D_{0}=20 \mathrm{~mm}$. The same phenomenon as in Fig. 4 can be seen. The flames become more elongated in the downstream direction as the size of the conical end piece increases and the swirl number (Tab. 2) drops from $S=0.73$ to $S=0.61$. The relative flame luminosity $\bar{I} / \bar{I}_{\text {ref }}$ also features the same type of evolution as identified for the injectors of varying diameters. The luminosity drops from $\bar{I} / \bar{I}_{r e f}=1.09$ to 0.93 from left to right in Fig. 5 . One may again note that the flame gets closer to the sidewalls as it is pushed further downstream by reducing the swirl number.

The main conclusion from these experiments is that changing the injector diameter $D_{0}$ or the diameter $C$ of the conical end piece alters the flow the same way at the injector outlet. As the swirl number $S$ is reduced, the flame becomes less compact and
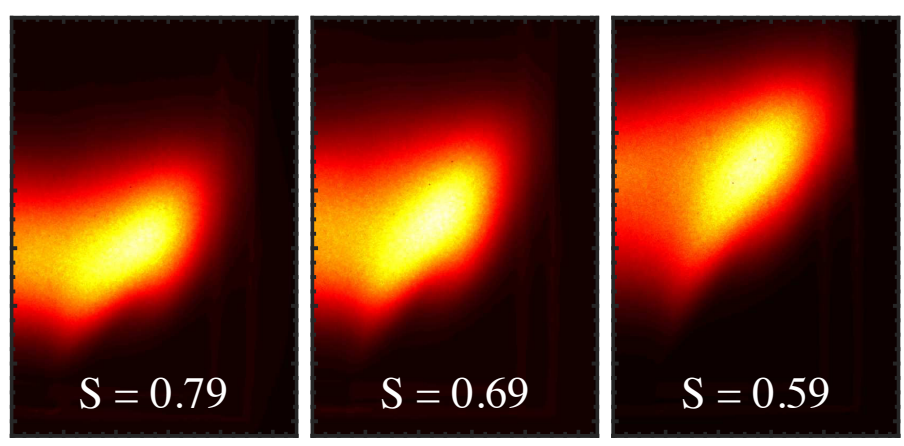

FIGURE 4. Flame shapes for swirler $3, C=12 \mathrm{~mm}$ and different injector diameters: from left to right $D_{0}=22,20$ and $18 \mathrm{~mm}$.
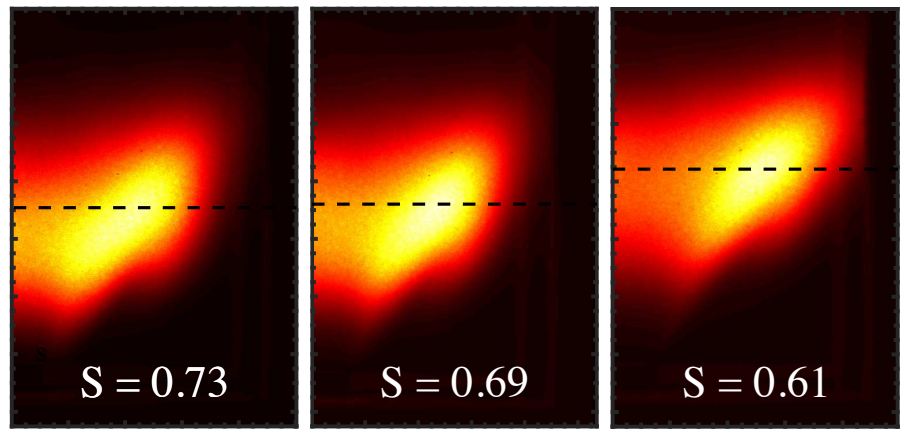

FIGURE 5. Flame shapes for swirler $3, D_{0}=20 \mathrm{~mm}$ and different cones: from left to right $C=10,12$ and $14 \mathrm{~mm}$. Superimposed on the images is the cutting line used for the analysis of heat release rate contributions presented in Figs. 11 and 12.

moves further away from the injector backplane with an intensification of heat losses to the chamber sidewalls. This in turn progressively reduces the average flame luminosity of these flames featuring the same equivalence ratio $\phi=0.82$ and thermal power $5.44 \mathrm{~kW}$.

When the swirl number $S$ increases, the flame becomes more compact and is stabilized closer to the injector exit. If the swirl level is too large, flashback is observed for $S>0.84$. The pressure drop through the different injectors tested is also reported in Tab. 2, and one may conclude that it barely changes in these experiments conducted at low injection Reynolds number.

\section{FLAME TRANSFER FUNCTION}

The FTF is determined from Eq. (1) by submitting the flame to harmonic modulations of the flowrate. The velocity fluctuation $u^{\prime}$ is deduced from the hot wire measurements. This probe is located in the nozzle of the convergent piece in Fig. 1. It has been checked that the velocity has a top hat profile with a low level of 


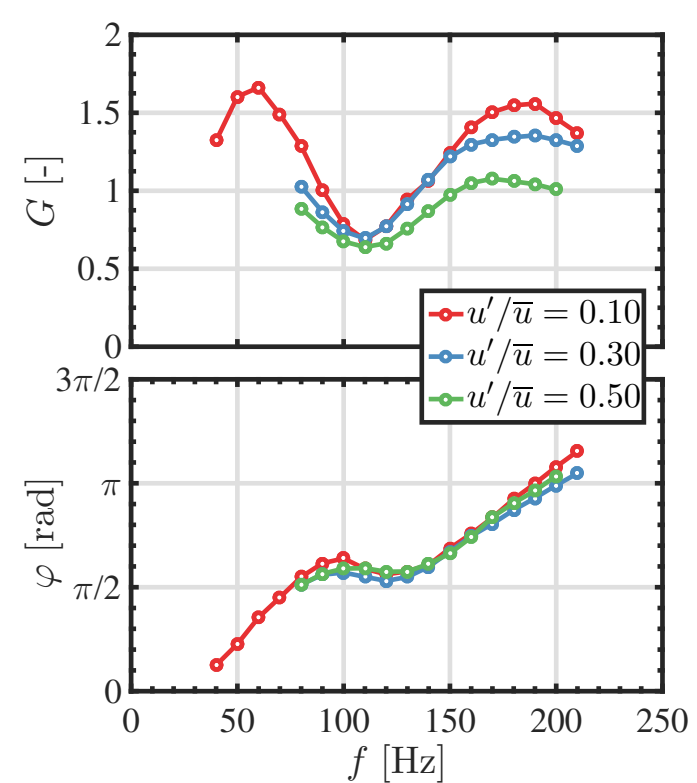

FIGURE 6. FTF for Swirler $3, D_{0}=20 \mathrm{~mm}$ and $C=12 \mathrm{~mm}$.

turbulence at this location. The photomultiplier with the $\mathrm{OH}^{*}$ filter is used to determine the mean $\bar{I}$ and fluctuating $I^{\prime}$ luminosity signals integrated over the flame volume and over the line of sight. These signals are assumed to be a good tracer of the heat release rate. The transfer function is deduced from the cross and power-spectral density of these signals examined at the forcing frequency $f$. They were recorded at a sampling rate of $f_{s}=8192$ $\mathrm{Hz}$ over 4 seconds and Welch periodograms were used to obtain statistically converged results. FTF data are presented in the frequency range $40-210 \mathrm{~Hz}$ for different velocity perturbation levels $u^{\prime} / \bar{u}$, where $\bar{u}$ and $u^{\prime}$ denote the mean and root-mean-square values of the signal measured by the hot wire.

\section{Effects of the perturbation level}

The FTF of Swirler 3 with the $D_{0}=20 \mathrm{~mm}$ injector diameter and the $C=12 \mathrm{~mm}$ conical end piece is investigated in Fig. 6 for three forcing levels $u^{\prime} / \bar{u}=0.10,0.30$ and 0.50 . The response is very similar to that found by Palies et al. [5] and in many other studies. The FTF phase lag is found to remain roughly independent of the forcing level. The phase lag at zero frequency does not reach zero here because the reference velocity for FTF phase lag calculations is taken at the hot wire location and not at the burner outlet. The drop observed for the FTF gain as the perturbation level increases reflects the progressive saturation of the flame response at high forcing amplitude. The gain first increases with the frequency to reach a maximum at $f=60 \mathrm{~Hz}$ for $u^{\prime} / \bar{u}=0.10$. It then features a sudden drop with a valley and a minimum at about $110 \mathrm{~Hz}$, which is found to be roughly independent of the forcing level. This frequency also corresponds to an inflection point in the FTF phase plot. At higher frequencies, the FTF gain increases again to reach a second maximum at about $f=190 \mathrm{~Hz}$ for $u^{\prime} / \bar{u}=0.10$. This peak value and the associated frequency now depend on the forcing level. These features were already described in $[5,20]$. The drop of the FTF gain in the intermediate frequency range is associated to swirl number oscillations that were shown to lead to large heat release rate disturbances at the flame bottom that destructively interfere with those acting at the flame tip and associated to flame-vortex roll-up [3].

The next objective is to analyze how the FTF gain valley could be deepened when the injector geometry is modified. The frequency at which the FTF gain is the lowest is controlled by the distance between the swirler and the injector outlet [12]. It has been shown that this minimum value weakly depends on the velocity forcing level and further experiments are mainly reported for $u^{\prime} / \bar{u}=0.10$ except for flame visualization.

\section{Effects of the injector geometry}

Figure 7 shows the measured FTF for the three swirler designs tested in this study (Tab. 1). The size of the conical end piece is fixed in these experiments to $C=12 \mathrm{~mm}$ and the injector diameter is varied from $D_{0}=18$ to $22 \mathrm{~mm}$. For a fixed injector geometry, one may estimate the swirl number $S$ by assuming a uniform flow profile for the axial velocity in the injection tube and an azimuthal velocity linearly increasing with the radial distance to the axis. It is important to underline that under these assumptions, the swirl number progressively decreases from Swirler 2 to Swirler 4 for a fixed injection tube diameter $D_{0}$ and that these numbers increase when $D_{0}$ increases.

Results for the smaller injection tube of diameter $D_{0}=$ $18 \mathrm{~mm}$ are shown at the top in Fig. 7(a). The FTF phase lag remains independent of the swirler design. The FTF gain plots of Swirler 2 and Swirler 3 also collapse on the same curve. The only difference is observed for Swirler 4 that features higher gain values for $f \geq 80 \mathrm{~Hz}$. The main conclusion is that when the injection tube is too small, the FTF gain does not drop below unity for the three swirler designs tested.

Results for an injection tube diameter increased to $D_{0}=$ $20 \mathrm{~mm}$ are shown in Fig. 7(b). The same observations as in Fig. 7(a) can be made. The FTF phase lags of the different swirlers roughly collapse on the same curve except near the inflection point for Swirler 4. Differences between maxima and the minimum gain values of the FTF are now larger with this injection tube $D_{0}=20 \mathrm{~mm}$ than those presented in Fig. 7(a) for $D_{0}=18 \mathrm{~mm}$. This design allows to get a slight attenuation of the incoming perturbations around $f=110 \mathrm{~Hz}$ with a minimum gain value of about $G \sim 0.6$. The FTF gain curves for Swirler 2 and Swirler 3 still match over the entire frequency range explored and that obtained for Swirler 4 is offset to lower frequencies with slightly larger gain values. 

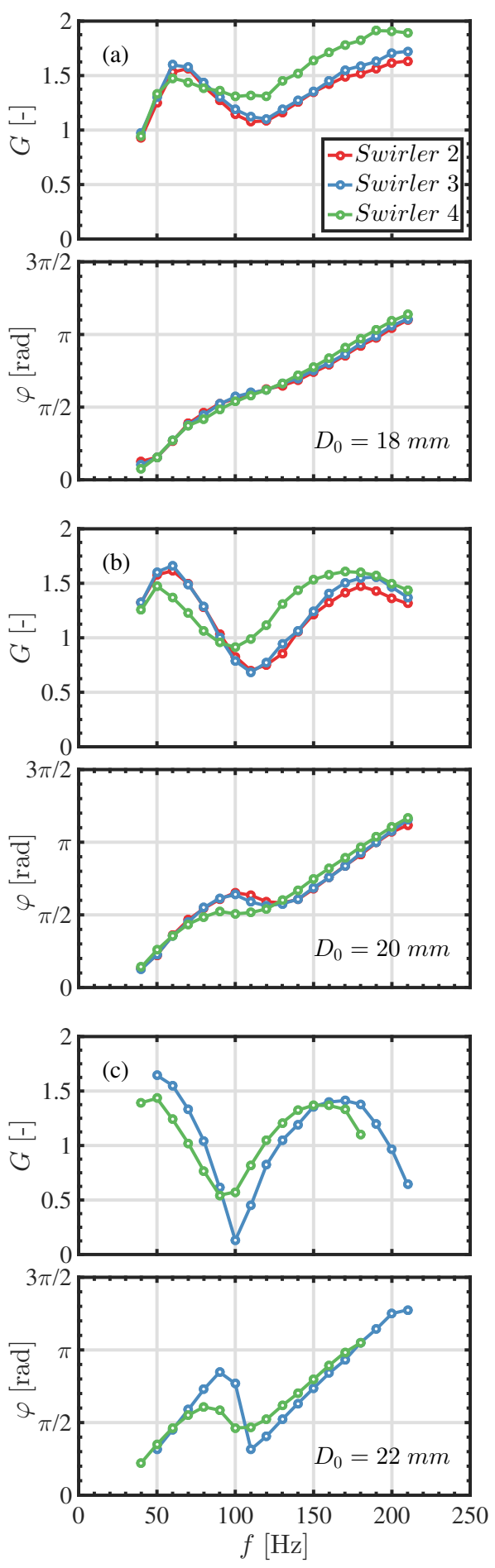

FIGURE 7. FTF for Swirler 2 (red), Swirler 3 (blue) and Swirler 4 (green) with $C=12 \mathrm{~mm}$ and $D_{0}=18 \mathrm{~mm}$ (a), $D_{0}=20 \mathrm{~mm}$ (b) and $D_{0}=22 \mathrm{~mm}$ (c). $u^{\prime} / \bar{u}=0.10$.
The FTF obtained for the largest injection tube of diameter $D_{0}=22 \mathrm{~mm}$ are examined in Fig. 7(c). Data could only be measured for Swirler 3 and Swirler 4. For Swirler 2, featuring the highest swirl number $S=0.81$, the flame flashes back into the injection tube when it is submitted to flowrate modulations even for a forcing level as low as $u^{\prime} / \bar{u}=0.05$. It has already been indicated that when the swirl $S_{0}$ is larger than 0.84 , flash back takes place at steady injection conditions. The transition to flashback is triggered here by the flow modulation when the swirl number dangerously approaches the critical value of 0.84 . The FTF obtained with Swirler 3 and Swirler 4 now differ for this injection tube diameter. The FTF gain drops to $G \sim 0.1$ with Swirler 3 at $f=100 \mathrm{~Hz}$ leading to the largest attenuations of the incoming perturbations. The FTF gain reaches $G \sim 0.5$ at $f=90 \mathrm{~Hz}$ for Swirler 4. It is also worth noting that the maximum gain values reached by these FTF are about the same as those found for the FTF with the lower injection diameters $D_{0}=20$ and $18 \mathrm{~mm}$ shown in Figs. 7(a-b).

These results indicate that the minimum gain value that the FTF can reach decreases as the swirl number increases. For a fixed injection tube diameter, the FTF gain minimum slightly drops as the swirler design is optimized to increase the swirl number. Increasing the injection tube diameter has a larger impact on the FTF than optimizing the swirler design. Increasing the injection tube diameter leads to larger swirl numbers and to lower gain values of the FTF up to a critical point where the flame flashes back inside the injector.

Results for Swirler 3 leading to the lowest flame response without flashback risks are now analyzed in more details. Swirl numbers were measured at the outlet of the injectors equipped with this swirler for the configurations indicated in Tab. 2. Figure 8 show the FTF measurements when the injector diameter is varied and the conical end piece diameter is fixed to $C=12 \mathrm{~mm}$. These data are reproduced from Fig. 7. They confirm that the minimum FTF gain value progressively drops when the swirl number increases from $S=0.59$ for $D_{0}=18 \mathrm{~mm}$ to $S=0.79$ for $D_{0}=22 \mathrm{~mm}$. One may also note that the corresponding frequency slightly reduces from $f=120 \mathrm{~Hz}$ to $f=100 \mathrm{~Hz}$ when $D_{0}$ is increased from 18 to $22 \mathrm{~mm}$. This frequency shift is attributed to the increase of the bulk flow velocity inside the injection tube as its diameter is reduced. It was shown in $[5,12,14]$ that the convection time between the swirler and the injector outlet fully determines this frequency.

The same type of features can be obtained by operating the injector with a fixed diameter $D_{0}=20 \mathrm{~mm}$, but with different conical end pieces. Results in Fig. 9 are plotted for two forcing levels $u^{\prime} / \bar{u}=0.10$ and 0.30 . One may again check that the minimum gain value reached here at $f=110 \mathrm{~Hz}$ remains independent of this level. The FTF gain at $f=110 \mathrm{~Hz}$ now drops from $G=1$ for $C=14 \mathrm{~mm}$ to $G \sim 0.3$ for $C=10 \mathrm{~mm}$. Reducing the diameter $C$ of the conical end piece corresponds to configurations where the swirl number increases from $S=0.61$ for 

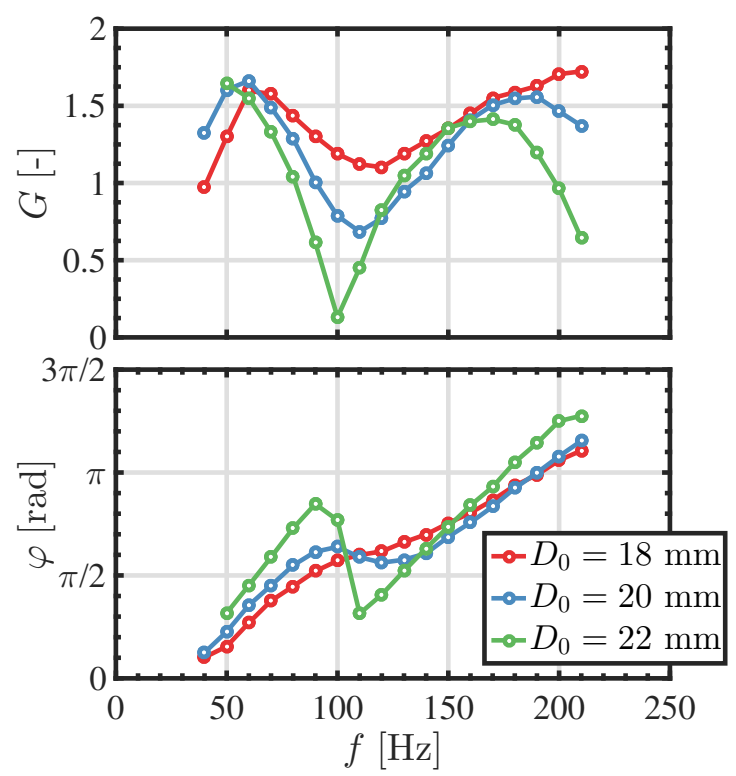

FIGURE 8. FTF for Swirler 3 with $C=12 \mathrm{~mm}$ and $D_{0}=18,20$ and $22 \mathrm{~mm} . u^{\prime} / \bar{u}=0.10$.

$C=14 \mathrm{~mm}$ to $S=0.73$ for $C=10 \mathrm{~mm}$ (Tab. 2). It is however worth noting that the frequency associated with the minimum gain does not change in these cases. These three injectors feature the same injection tube diameter $D_{0}=20 \mathrm{~mm}$ and the bulk flow velocity remains unchanged in these elements. Modifying the conical end piece barely alters the time lag of flow disturbances convected between the swirler and the injector outlet and the frequency corresponding the minimum gain value remains unchanged. One may also note that the peak gain values reached at $f=190 \mathrm{~Hz}$ also drop when the diameter $C$ of the conical end piece is reduced and the swirl number $S$ at the injector outlet increases. This drop of the FTF gain maxima is also visible in Fig. 8 between $f=150$ and $210 \mathrm{~Hz}$.

The flame response to acoustic forcing is found to mostly depend on level of swirl. The same mechanisms operate when one substitutes the swirler, modify the injector tube diameter or modify the central insert cone diameter as shown by the FTF plotted in Figs. 7 to 9 for the different geometries of the injector. Three selected configurations are further analyzed in the next section by phase conditioned images describing the flame response to the incoming flow perturbations. Since the swirl number $S$ varies more when the flow passage area is modified, in comparison to when the swirler is changed, the configurations retained to illustrate the changes in the flame dynamics corresponds to Swirler 3 with an injection tube diameter $D_{0}=20 \mathrm{~mm}$ and different conical end pieces (Tab. 2).

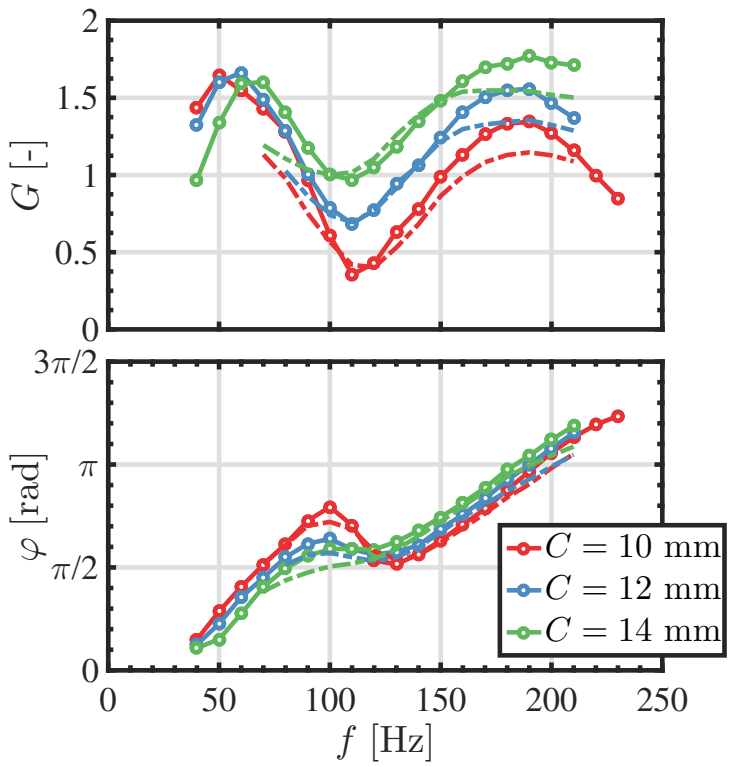

FIGURE 9. FTF for Swirler 3 with $D_{0}=20 \mathrm{~mm}, C=10,12$ and $14 \mathrm{~mm}$. Solid lines withs symbols : $u^{\prime} / \bar{u}=0.10$. Dashed-lines: $u^{\prime} / \bar{u}=0.30$.

\section{FLAME DYNAMICS}

Phase averaged images of the flame motion conditioned by the harmonic forcing signal are examined at two frequencies. The first one is set to $f=110 \mathrm{~Hz}$ and corresponds to situations where the FTF gain is minimum in Fig. 9. The second frequency explored is set to $f=190 \mathrm{~Hz}$ and corresponds to situations with large FTF gain values in Fig. 9. The perturbation level is fixed here to $u^{\prime} / \bar{u}=0.30$ in order to better highlight the differences. Six phase conditioned images are plotted in Fig. 10 covering a full cycle of oscillation. Each image, separated by a phase angle of 60 degrees, is formed by accumulating one hundred snapshots with an exposure of $43 \mu$ s each. An Abel deconvolution is then used to reveal the trace of the flame luminosity in a longitudinal plane crossing the burner axis. Care has been taken to record these images with the same camera settings and exposure times, so that the relative levels of flame luminosity can directly be compared.

An examination of the first sequence in Fig. 10(a)-left indicates that both the flame motion and the luminosity oscillations are quite weak. This is consistent with the low value of the FTF gain measured at this forcing frequency in Fig. 9 for a conical end piece with $C=10 \mathrm{~mm}$. For the same injector, but at a forcing frequency $f=190 \mathrm{~Hz}$, the situation is quite different in the right sequence in Fig. 10(a, right). Flame tip roll-up becomes more evident and luminosity oscillations are more pronounced. The FTF gain level is indeed much higher at this forcing frequency in Fig. 9. The flame motion and the luminosity oscillations are even more marked in the left and right series of images 


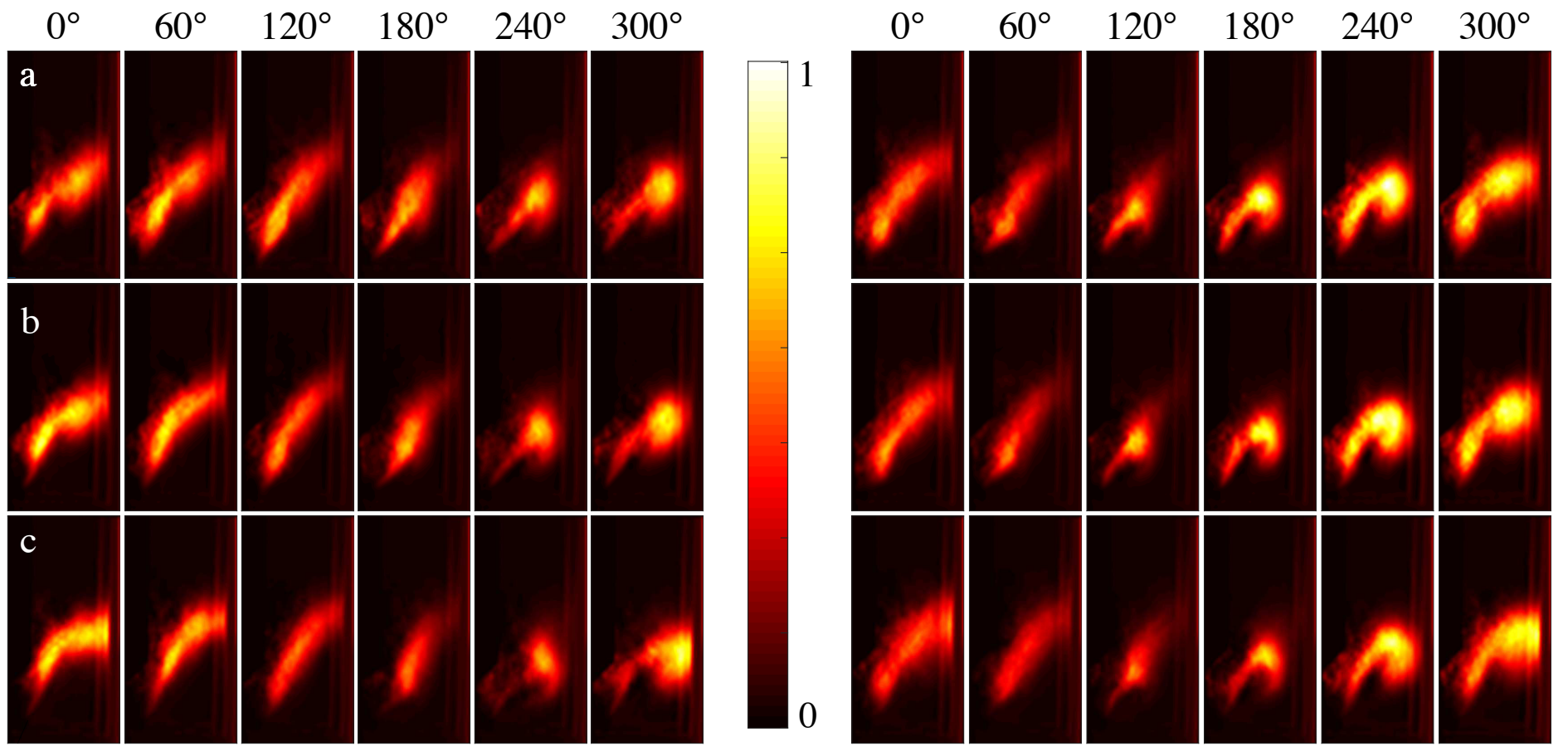

FIGURE 10. Abel deconvoluted phase averaged images at the forcing frequencies $f=110 \mathrm{~Hz}$ (left images) and $f=190 \mathrm{~Hz}$ (right images). Swirler 3, $D_{0}=20 \mathrm{~mm}$, (a) $C=10 \mathrm{~mm}$, (b) $C=12 \mathrm{~mm}$, (c) $C=14 \mathrm{~mm} \cdot u^{\prime} / \bar{u}=0.30$.

in Fig. 10(c) obtained for the injector with the conical end piece of $C=14 \mathrm{~mm}$ diameter. For this injector, the FTF gain level is greater than unity in Fig. 9 at both $f=110$ and $190 \mathrm{~Hz}$ forcing frequencies. A close-up view of the six cases presented in Fig. 10 indicate that the global flame motion is not so much altered between results at $f=110 \mathrm{~Hz}$ and $190 \mathrm{~Hz}$. The main differences are more related to fluctuations of the flame luminosity.

It was shown in [5] that at the frequency corresponding to a local minimum in the FTF gain, the bottom and top parts of the flame operate in phase opposition and their heat release rate oscillations almost cancel out one another. At the frequency corresponding to a local maximum, the situation is different. The contributions from the bottom and top parts of the flame to the heat release rate oscillations are in phase and their combination gives a maximum level. The same kind of analysis is carried out here for the flames investigated in Fig. 10. At first two interrogation windows are defined for each configuration by analyzing the mean flame structure under steady injection condition in Fig. 5. For each flame, the separation line between the bottom and the top of the image is defined such that the contribution to the total luminosity intensity of the upper and lower windows are equal. The pixel intensities of the six phase-averaged images are then summed for the top and bottom windows. The fluctuating $I^{\prime}$ and mean $\bar{I}$ intensities in each window are deduced. Finally, the fluctuations $I^{\prime} / \bar{I}$ in the two windows can be compared.
The results shown in Figs. 11 and 12 slightly contrast with those found by Palies et al. [5]. For the configuration with the $C=10 \mathrm{~mm}$ cone diameter featuring the largest swirl number $S=0.73$, the upper and bottom heat release rate oscillations are clearly in phase-opposition at the forcing frequency $f=110 \mathrm{~Hz}$ corresponding to a minimum FTF gain level in Fig. 9. This interfering mechanism is that demonstrated in [5]. But at the same time, the level of oscillations in both windows is very low in the top plots in Fig. 11. The level of heat release rate oscillations in the upper and lower windows appears as another mechanism leading to a low or a high FTF gain value. This mechanism is confirmed by the results presented for the other injector configurations in Figs. 11 and 12. It appears that the FTF gain level is directly proportional to the oscillation level in the two windows.

At $f=110 \mathrm{~Hz}$, the minimum FTF gain value first increases due to a slight change of the phase lag between the heat release rate contributions in the lower and upper windows in Fig. 11center, but also because of a slight increase of both signal levels in each window compared to Fig. 11-top. The FTF gain then further increases at this forcing frequency in Fig. 11-bottom mainly because of higher levels of heat release fluctuations in the bottom window while the phase lag between the signals in the two windows remains unchanged.

At the forcing frequency $f=190 \mathrm{~Hz}$, the situation is simpler. The heat release rate oscillations in the bottom and top 

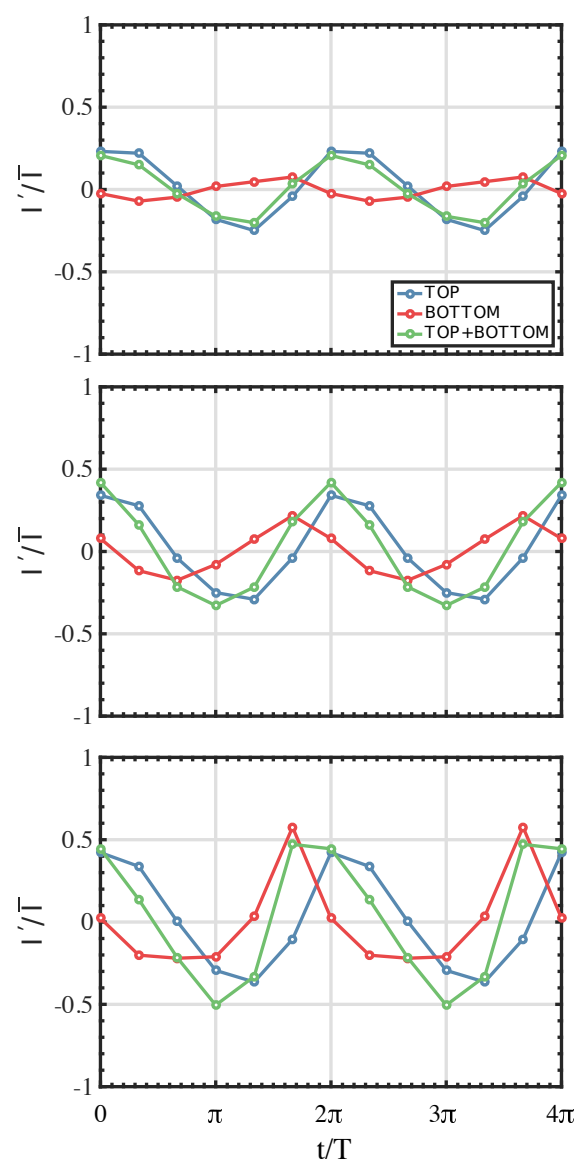

FIGURE 11. Fluctuating heat release rate signals at the forcing frequency $f=110 \mathrm{~Hz}$ reconstructed from the light emission detected in the upper and lower windows delineated in Fig. 5. Swirler 3, $D_{0}=20 \mathrm{~mm}$, $C=10 \mathrm{~mm}$ (top), $C=12 \mathrm{~mm}$ (center) and $C=14 \mathrm{~mm}$ (bottom). $u^{\prime} / \bar{u}=0.30$.

windows in Fig. 12 are quasi in phase and the phase lag remains constant for the three injectors. The maximum FTF gain at $f=190 \mathrm{~Hz}$ increases in Fig. 9 because the injectors equipped with the conical end piece of diameters $C=10,12$ and $14 \mathrm{~mm}$ lead to in phase larger heat release rate fluctuations in both the lower and upper parts of the flame. The origin of these different responses will be investigated in future work with more detailed flow analysis.

\section{CONCLUSION}

Experiments were carried out to investigate changes of the flame transfer function (FTF) of swirl-stabilized lean premixed methane/air flames when the system is operated at constant equivalence ratio $\phi=0.82$ and constant thermal power $\mathscr{P}=$ $5.44 \mathrm{~kW}$ with different injectors. Three radial swirling vanes
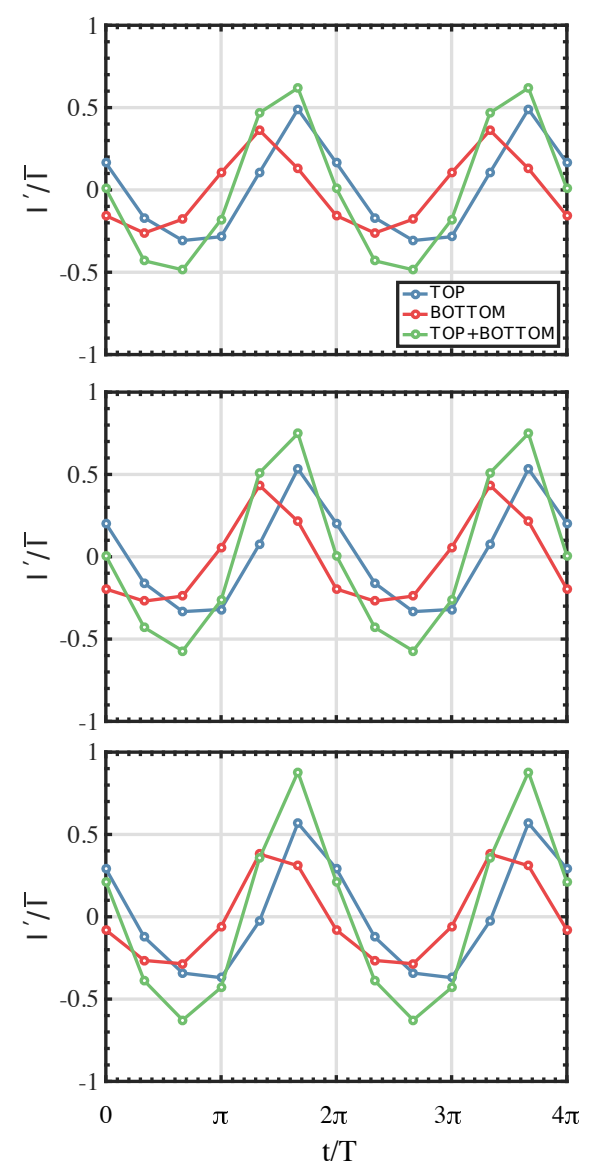

FIGURE 12. Fluctuating heat release rate signals at the forcing frequency $f=190 \mathrm{~Hz}$ reconstructed from the light emission detected in the upper and lower windows delineated in Fig. 5. Swirler 3, $D_{0}=20 \mathrm{~mm}$, $C=10 \mathrm{~mm}$ (top), $C=12 \mathrm{~mm}$ (center) and $C=14 \mathrm{~mm}$ (bottom). $u^{\prime} / \bar{u}=0.30$.

with cylindrical injection holes yielding an increasing level of swirl were tested. The distance between the swirler and the injector outlet was kept constant. Effects of a reduction of the diameter of the injection tube and of the size of the conical end-piece used as a central bluff-body were investigated.

It is found that the FTF of these swirling-flames features a drop of the gain in the intermediate frequency range. The frequency corresponding to this minimum shifts to lower frequencies as the bulk flow velocity decreases in the injection tube. These observations are in agreement with previous analysis of the response of swirling flames. A focus is then made on effects leading to the largest drop of the FTF gain at this forcing frequency. The main findings are : (1) increasing the swirl level of the swirler leads to a progressive reduction of the minimum gain achievable, (2) increasing the diameter of the injection tube or reducing the size of the conical end piece serving as a bluff- 
body leads to increased swirl levels and to further reduction of the FTF gain, (3) modifying the injector diameter changes the frequency associated to the minimum gain while changing the size of the conical end piece does not modify this frequency, (4) the minimum gain value remains to the first order unaltered by the velocity forcing level, and (5) the largest swirl number leads to the lowest FTF gain value, but too large swirl levels lead to flashback of the perturbed flame inside the injector.

The way the flame behaves has then been examined at two forcing frequencies corresponding to those associated with the minimum and the maximum flame responses. When the FTF gain is the highest, analysis of the lower and upper parts of the flame dynamics indicate that the two contributions to heat release are almost in phase and the level of heat release increases in each window as the swirl number is reduced without modifications of their phase shift. Analysis of the flame dynamics at the minimum response reveals a more complex behavior. The lowest flame response is found for the injector featuring the largest swirl number. In this case, the bottom and upper parts of the flame heat release responses are out of phase in agreement with previous findings. However, experiments also reveal that the level of heat release fluctuations remains also weak in both the lower and upper parts of the flame. For the injector designs with lower swirl numbers, the heat release rate response first increases due both to a detuning of the phase lag between the bottom and upper contributions to heat release rate fluctuations and to an increase of the signal levels in both windows. As the swirl number is further reduced, the drop in the FTF disappears because the level of heat release fluctuations in the upper and lower parts of the flame further increase without modification of their phase relationship.

\section{ACKNOWLEDGMENTS}

This project has received funding from the European Union's Horizon 2020 research and innovation programme under the Marie Sklodowska-Curie grant agreement No 643134. This work is supported by Agence Nationale de la Recherche, NOISEDYN project (ANR-14-CE35-0025-01). The authors are thankful to the technical staff of EM2C laboratory for their help.

\section{REFERENCES}

[1] Lieuwen, T. C., and Yang, V., eds., 2005. Combustion instabilities in gas turbines, Operational experience, Fundamental mechanisms, and Modeling, Vol. 210 of Progress in Astronautics and Aeronautics. American Institute of Aeronautics and Astronautics, Inc.

[2] Huang, Y., and Yang, V., 2009. "Dynamics and stability of lean-premixed swirl-stabilized combustion". Progress in Energy and Combustion Science, 35(4), pp. 293-384.

[3] Candel, S., Durox, D., Schuller, T., Bourgouin, J.-F., and
Moeck, J., 2014. "Dynamics of swirling flames". Annual Review of Fluid Mechanics, 46, pp. 147-173.

[4] Ducruix, S., Schuller, T., Durox, D., and Candel, S., 2003. "Combustion dynamics and instabilities: Elementary coupling and driving mechanisms". Journal of Propulsion and Power, 19(5), pp. 722-734.

[5] Palies, P., Durox, D., Schuller, T., and Candel, S., 2010. "The combined dynamics of swirler and turbulent premixed swirling flames". Combustion and Flame, 157, pp. 16981717.

[6] Cosic, B., Terhaar, S., Moeck, J., and Paschereit, C., 2015. "Response of a swirl-stabilized flame to simultaneous perturbations in equivalence ratio and velocity at high oscillation amplitudes". Combustion and Flame, 162, pp. 10461062.

[7] Hirsch, C., Fanaca, D., Alemela, R., Polifke, W., and Sattelmayer, T., 2005. "Influence of the swirler design on the flame transfer function of premixed flames". In ASME Turbo Expo 2005, no. GT2005-68195, ASME 2005 Gas Turbine Technical Congress \& Exposition.

[8] Palies, P., Schuller, T., Durox, D., and Candel, S., 2011. "Modeling of swirling flames transfer functions". Proceedings of the Combustion Institute, 33, pp. 2967-2974.

[9] Acharya, V., Shreekrishna, Shin, D., and Lieuwen, T., 2012. "Swirl effects on harmonically excited, premixed flame kinematics". Combustion and Flame, 159, pp. 11391150.

[10] Palies, P., Schuller, T., Durox, D., Gicquel, L., and Candel, S., 2011. "Acoustically perturbed turbulent premixed swirling flames". Physics of Fluids, 23(037101), 15 pages.

[11] Acharya, V., and Lieuwen, T., 2015. "Effects of azimuthal flow fluctuations on flow and flame dynamics of axisymmetric swirling flames". Physics of Fluids, 27(105106), 17 pages.

[12] Komarek, T., and Polifke, W., 2010. "Impact of swirl fluctuations on the flame response of a perfectly premixed swirl burner". Journal of Engineering for Gas Turbine and Power, 132(061503), 7 pages.

[13] Palies, P., Durox, D., Schuller, T., and Candel, S., 2011. "Acoustic-convective mode conversion in an airfoil cascade". Journal of Fluid Mechanics, 672, pp. 545-569.

[14] Bunce, N., Quay, B., and Santavicca, D., 2014. "Interaction between swirl number fluctuations and vortex shedding in a single-nozzle turbulent swirling fully-premixed combustor". Journal of Engineering for Gas Turbine and Power, 136(021503), 11 pages.

[15] Mirat, C., Durox, D., and Schuller, T., 2015. "Stability analysis of a swirled spray combustor based on flame describing function". Proceedings of the Combustion Institute, 35, pp. 3291-3298.

[16] Giuliani, F., Gajan, P., Diers, O., and Ledoux, M., 2002. "Influence of pulsed entries on a spray generated by an air- 
blast injection device: An experimental analysis on combustion instability processes in aeroengines". Proceedings of the Combustion Institute, 29, pp. 91-98.

[17] Straub, D., and Richards, G., 1999. "Effect of axial swirl vane location on combustion dynamics". In ASME Paper 99-GT-109.

[18] Guiberti, T., Durox, D., Scouflaire, P., and Schuller, T., 2015. "Impact of heat loss and hydrogen enrichment on the shape of confined swirling flames". Proceedings of the Combustion Institute, 35, pp. 1385-1392.

[19] Tay Wo Chong, L., Komarek, T., Zellhuber, M., Hirsch, C., and Polifke, W., 2016. "Combined influence of strain and heat loss on turbulent premixed flame stabilization". Flow, Turbulence and Combustion 97, pp. 263-294.

[20] Palies, P., Durox, D., Schuller, T., and Candel, S., 2011. "Experimental study on effects of swirler geometry and swirl number on flame describing functions". Combustion Science and Technology, 183, pp. 704-717. 